\title{
Nutrition and Healthy Ageing: Calorie Restriction or Polyphenol-Rich "MediterrAsian” Diet?
}

\author{
Kathrin Pallauf, Katrin Giller, Patricia Huebbe, and Gerald Rimbach \\ Institute of Human Nutrition and Food Science, Christian-Albrechts University of Kiel, Hermann-Rodewald-Straße 6, \\ 24118 Kiel, Germany
}

Correspondence should be addressed to Gerald Rimbach; rimbach@foodsci.uni-kiel.de

Received 20 June 2013; Accepted 26 July 2013

Academic Editor: David Vauzour

Copyright (C) 2013 Kathrin Pallauf et al. This is an open access article distributed under the Creative Commons Attribution License, which permits unrestricted use, distribution, and reproduction in any medium, provided the original work is properly cited.

Diet plays an important role in mammalian health and the prevention of chronic diseases such as cardiovascular disease (CVD). Incidence of CVD is low in many parts of Asia (e.g., Japan) and the Mediterranean area (e.g., Italy, Spain, Greece, and Turkey). The Asian and the Mediterranean diets are rich in fruit and vegetables, thereby providing high amounts of plant bioactives including polyphenols, glucosinolates, and antioxidant vitamins. Furthermore, oily fish which is rich in omega-3 fatty acids is an important part of the Asian (e.g., Japanese) and also of the Mediterranean diets. There are specific plant bioactives which predominantly occur in the Mediterranean (e.g., resveratrol from red wine, hydroxytyrosol, and oleuropein from olive oil) and in the Asian diets (e.g., isoflavones from soybean and epigallocatechin gallate from green tea). Interestingly, when compared to calorie restriction which has been repeatedly shown to increase healthspan, these polyphenols activate similar molecular targets such as Sirtl. We suggest that a so-called "MediterrAsian" diet combining sirtuin-activating foods (= sirtfoods) of the Asian as well as Mediterranean diet may be a promising dietary strategy in preventing chronic diseases, thereby ensuring health and healthy ageing. Future (human) studies are needed which take the concept suggested here of the MediterrAsian diet into account.

\section{Introduction}

It has been well established that diet plays a central role in maintaining health throughout life. In the Western world diet has significantly changed in recent years. Diets that are rich in saturated fats and cholesterol, low in fibre, and high in sugar and salt may increase the CVD risk [1-3]. We are currently facing an increase in the incidence of obesity associated diseases in general and specifically coronary heart disease in many parts of the world. Contrarily, a reduction of food and/or calorie intake without malnutrition may be associated with the prolongation of life- and healthspan. The National Academies Keck Futures Initiative; the Future of Human Healthspan, defined healthspan as the time an organism was of good health with health being the "the ability of a system to maintain or return to homeostasis in response to challenges" [4]. In mammals including primates, calorie restriction (CR) repeatedly delayed disease onset, thereby prolonging healthspan [5-7]. As diet composition also seems to influence health $[8,9]$, it has been hypothesized that CR and certain dietary factors can prevent age-related diseases like atherosclerosis and cardiovascular disease (CVD), type 2 diabetes mellitus, neurodegenerative diseases, and cancer. Dietary factors that decrease CVD risk may be the consumption of red wine and olive oil in the Mediterranean area [10] or seaweed in coastal Asia [11]. Interestingly, polyphenol consumption and calorie restriction (CR) seem to have similar effects on metabolism in humans [12, 13], and supplementation with polyphenols may attenuate negative effects from a high fat diet in mice [14]. Therefore, polyphenols are also referred to as CR mimetics. An important mechanism by which polyphenols induce CR-like signalling pathways seems to function through sirtuin activation [15]. Sirtuins are NAD-dependent deacetylases that were shown to be involved in the regulation of lifespan and metabolism in different organisms $[15,16]$. Further evidence exists supporting a role of polyphenols in gene regulation via the gamma coactivator 1-alpha (PGC-1 $\alpha$ ) and transcription factors such as nuclear factor-erythroid 2 (Nrf2), forkhead box $\mathrm{O}$ (FoxO), and nuclear factor kappa $\mathrm{B}(\mathrm{NF} \kappa \mathrm{B})$ [17], all of which are also implicated in CR-mediated effects. In this review we will discuss the literature on $\mathrm{CR}$ and foods that induce CR-like 
effects with a special focus on sirtuin activators that are found in the Asian and Mediterranean diets and their potential to promote healthy ageing. Because of their sirtuin-activating properties we refer to these foodstuffs as "sirtfoods".

\section{Signalling Pathways That Are Induced by Calorie Restriction}

CR induces body weight loss and has beneficial effects on plasma levels of triglycerides and cholesterol as well as on blood pressure, thereby preventing or delaying the onset of age-related diseases [18]. Additionally, in response to a reduction of body fat, adipose tissue-derived hormones including leptin and adiponectin are modulated. These hormones are central in the regulation of satiety and appetite in the hypothalamus [19]. As an important regulator of body weight [20], circulating leptin levels are directly proportional to the total amount of visceral adipose tissue. While CR decreases leptin levels, it increases adiponectin levels. In contrast to leptin, adiponectin exhibits antiatherogenic, anti-inflammatory, and insulin-sensitizing properties and is assumed to be cardioprotective [21].

\subsection{Insulin-Like Growth Factor and Mammalian Target of} Rapamycin Signalling. One of the main impacts of dietary restriction is the modulation of insulin and insulin-like growth factor-1 (IGF-1) signalling [22]. Interestingly, in mice impaired IGF-1 signalling leads to a similarly prolonged lifespan as compared to CR [23] and in Caenorhabditis elegans inactivation of the IGF/PI3K/Akt pathway promoted longevity [24].

Upon binding to their receptors, insulin and IGF-1 induce a number of signalling pathways and kinases such as the phosphatidylinositol 3-kinases class I (PI3KI), the serine/threonine kinase Akt, and the mammalian target of rapamycin (mTOR). mTOR promotes protein synthesis and cellular growth [25]. Besides downregulating mTOR via lowering IGF/PI3K/Akt signalling, CR also inhibits mTOR through activation of the $5^{\prime}$ adenosine monophosphateactivated protein kinase (AMPK) [26]. Inhibition of mTOR leads to prolongation of lifespan [27] which is in part mediated by autophagy, a lysosomal degradation process that degrades no-longer-needed proteins and organelles and also functions as a starvation response [28]. Consistent with CR attenuating age-related changes in metabolism and cellular functions, insulin sensitivity and autophagic activity decrease with age while being increased by CR [29].

\subsection{Reactive Oxygen Species and the Hormesis Effect. Ageing} is also characterized by accumulating oxidative damage. There are different mechanisms that lead to this build-up of damaged proteins, lipids, and organelles. Damaged macromolecules may accumulate because of reduced degradation, reduced antioxidant capacity, or increased reactive oxygen species production $[30,31]$.

It was shown that CR can decrease the mitochondrial release of reactive oxygen species (ROS) which contribute to this type of damage in ageing organisms [32]. However, recent studies have indicated that the metabolic rate increases with CR [33], and it has been hypothesized that deleterious substances including ROS may have beneficial effects at low concentrations. This concept of a biphasic dose-response with low and high doses of a substance mediating opposite effects is referred to as hormesis [34]. According to this concept, low doses of a certain substance benefit the organism by inducing adaptive effects. In line with the concept of hormesis, ROS may function as essential signalling molecules, for example, by regulating redox-sensitive transcription factors [35]. Because of a lack of energy supply under CR, mitochondrial activity and, as a consequence, oxidative phosphorylation in the respiratory chain could be enhanced, leading to increased ROS production [36].

2.3. The Redox-Regulated Transcription Factors Nrf2 and $N F \kappa B$. One of the targets of increased ROS production is the nuclear factor-erythroid 2- (NFE2-) related factor (Nrf2). This Cap'n'Collar basic leucine zipper transcription factor controls the expression of a large number of antioxidant and phase II detoxifying enzymes such as the NAD(P)H dehydrogenase (quinone) 1 (NQO1), the heme oxygenase 1 (HO-1), glutathione $S$-transferase (GST), the glutathione peroxidase (GPx), and the $\gamma$-glutamylcysteine synthetase ( $\gamma \mathrm{GCS})$ [3739]. In CR rodents, upregulation and increased activity of these gene products have been described repeatedly [40, 41].

The nuclear factor kappa $\mathrm{B}(\mathrm{NF} \kappa \mathrm{B})$ is also a redoxsensitive transcription factor that induces the expression of genes involved in inflammation and cellular proliferation [42]. Although $\mathrm{NF} \kappa \mathrm{B}$ is activated by ROS, various studies have reported downregulation of $\mathrm{NF} \kappa \mathrm{B}$ by $\mathrm{CR}[43,44]$. It has been suggested that $\mathrm{CR}$ increases cytoplasmic levels of $\mathrm{I} \kappa \mathrm{B}$ which impedes $\mathrm{NF} \kappa \mathrm{B}$ translocation into the nucleus. Additionally, CR may influence $\mathrm{NF} \kappa \mathrm{B}$ translocation by decreasing nucleophosmin (NPM) expression. NPM is a nuclear phosphoprotein that shuttles between the nucleus and the cytoplasm and promotes $\mathrm{NF} \kappa \mathrm{B}$ activity [45]. Moreover, CR may inhibit the transcription of the NF $\kappa$ B subunit RelA/p65 through Sirtl activation [46]. Considering that at a higher age $\mathrm{NF} \kappa \mathrm{B}$ activity and as a consequence inflammation seem to increase [47], the down-regulation of $\mathrm{NF} \kappa \mathrm{B}$ activity by $\mathrm{CR}$ may contribute to the ageing-related health benefits of CR.

2.4. Forkhead Box O Transcription Factors. The forkhead box $\mathrm{O}$ (FoxO) transcription factor family activates or represses gene expression of a wide variety of genes implicated in apoptosis, cell cycle and differentiation, DNA repair, and stress response [48, 49] and is also activated by CR [50]. Of the four human forkhead genes that have been identified so far (FoxO1, FoxO3, FoxO4 and FoxO6), FoxO3 has been identified as a longevity-associated gene in centenarians [51]. It has been suggested that FoxO transcription factors may be involved in longevity because of their ability to detoxify ROS and repair DNA damage.

FoxOs can be regulated by various mechanisms such as phosphorylation, acetylation, and proteasomal degradation. While under nutrient rich conditions, insulin/IGF-1 signalling leads to translocation of FoxO out of the nucleus 
TABLE 1: FoxO regulation by Sirt1.

\begin{tabular}{|c|c|c|c|}
\hline Cell culture & Treatment & Outcome & Reference \\
\hline HEK 293T & Stress conditions $\left(\mathrm{H}_{2} \mathrm{O}_{2}\right)$ & $\uparrow$ Interaction between Sirt1 and FoxO3 & {$[53]$} \\
\hline MEF Sirtl ${ }^{-/-}$ & $\begin{array}{l}\text { Treatment with LY } 294002 \text { (PI3K inhibitor): } \\
\text { wild type } \\
\text { Sirt1 }^{-/-}\end{array}$ & $\begin{array}{l}\uparrow \text { Acetylation of FoxO3 } \\
\uparrow \text { GADD45 (stress resistance) } \\
\downarrow \text { GADD45 }\end{array}$ & \\
\hline HepG2 & $\begin{array}{l}\text { Serum starvation }=>\text { FoxO translocation } \\
\text { into the nucleus }\end{array}$ & $\uparrow$ Deacetylation of FoxO1 by Sirtl & [55] \\
\hline HeLa & Sirtl overexpression & $\begin{array}{l}\downarrow \text { FoxO3 activity } \\
(\downarrow \text { FoxO3 target genes Bim/p27) }\end{array}$ & {$[54]$} \\
\hline HEK 293T & Inhibition of Sirtl & $\begin{array}{l}\downarrow \text { FoxO4 activity } \\
\downarrow \text { MnSOD } \\
\downarrow \text { p } 27\end{array}$ & {$[58]$} \\
\hline
\end{tabular}

Bim: Bcl-2 interacting mediator of cell death, proapoptotic protein; $\mathrm{H}_{2} \mathrm{O}_{2}$ : hydrogen peroxide; HEK-293T: human embryonic kidney 293 cells containing the $\mathrm{T}$ antigen from simian virus; HepG2: human liver carcinoma cell line; MEF: mouse embryonic fibroblasts; MnSOD: manganese superoxide dismutase, part of antioxidative defence; p27: cyclin-dependent kinase inhibitor, controls cell cycle progression; PI3K: phosphatidylinositol 3-kinase.

TABLE 2: Cellular localization, activity, and biological function of sirtuins 1-7 according to [63].

\begin{tabular}{llll}
\hline Sirtuin & Localization & Activity & Biological function \\
\hline Sirt1 & Nucleus/cytosol & Deacetylase & Cell survival/metabolism \\
Sirt2 & Cytosol & Deacetylase & Cell cycle \\
Sirt3 & Mitochondria & Deacetylase & Thermogenesis/metabolism \\
Sirt4 & Mitochondria & ADP-ribosyltransferase & Insulin secretion/metabolism \\
Sirt5 & Mitochondria & Deacetylase & Unknown \\
Sirt6 & Nucleus & ADP-ribosyltransferase & DNA repair \\
Sirt7 & Nucleolus & Unknown & rDNA transcription \\
\hline
\end{tabular}

ADP: adenosine diphosphate; rDNA: ribosomal desoxyribonucleic acid; Sirt: sirtuin.

and subsequent degradation, and CR leads to activation of FoxO-mediated transcription [50]. An important mechanism for FoxO activation under conditions of limited nutrient supply is its deacetylation by Sirtl [52] (see Table 1). It has been shown that Sirtl leads to a type of FoxO3 activation that counteracts oxidative stress while suppressing FoxO3induced apoptosis rather than leading to FoxO3-induced cell death [53]. The finding that Sirtl can inhibit the transcription of one set of genes while switching on the transcription of another type of target genes could explain the observation made by Motta and colleagues [54] who stated that Sirtlmediated deacetylation of FOXO3 led to its inhibition. However, in the case of FoxO1, Daitoku and coworkers [55] reported an upregulation via Sirt-mediated deacetylation. Interestingly, FoxO and the tumour suppressor p53 appear to be functionally linked as they can alter each other's functions [56]. Both FoxO and p53 are deacetylated by Sirtl, which thereby controls their activities. In addition, FoxO induces gene expression of Sirtl [57]. Therefore, it seems plausible that $\mathrm{CR}$, at least in part, leads to lifespan extension through regulating the insulin/IGF1, FoxO, and Sirtl network.

\section{Sirtuins, the Mammalian Homologues of the Yeast Longevity Gene SIR2}

Sirtuins (Sirt1-7) are NAD-dependent histone deacetylases [59]. All sirtuins contain a catalytic core domain but differ in the protein sequences surrounding this domain and their cellular localization [60]. They act as protein deacetylases and/or ADP-ribosyltransferases. As they require NAD, it has been suggested that their activity depends on the metabolic state of the cell. It has been hypothesized that sirtuins may link energy intake to lifespan [61]. An inhibitory mutation of the Sirtl ortholog SIR2 in yeast shortened lifespan, whereas overexpression of SIR2 extended lifespan [62]. Their cellular localizations, activities, and biological functions are listed in Table 2.

3.1. Sirt1 and the Control of Metabolism. Sirtl is the best studied sirtuin to date and is sometimes referred to as a guardian against cellular oxidative stress and DNA damage. Apart from deacetylating p53 and FoxO transcription factors, it was also shown to interact with $\mathrm{NF} \kappa \mathrm{B}$, the peroxisome proliferator-activated receptor gamma $(\operatorname{PPAR} \gamma)$, and the PPAR $\gamma$ coactivator and inducer of mitochondrial biogenesis PGC-1 $\alpha[64,65]$ (Figure 1). In vivo studies have shown that CR upregulates the mammalian Sirtl protein levels in muscle, brain, fat, and kidney (see Table 3 ) $[57,66]$. In white adipose tissue (WAT) Sirtl was shown to deacetylate and inhibit $\operatorname{PPAR} \gamma$. This nuclear receptor which is induced by fatty acids activates fat synthesis and adipogenesis. Thus, inhibition of PPAR $\gamma$ by Sirtl led to fat loss [64]. A decrease in adipose tissue generally lowers the leptin/adiponectin ratio, thereby favouring insulin sensitivity and healthy ageing. It has also 
TABLE 3: Effects of calorie restriction or starvation on Sirtl in different tissues in mice and rats.

\begin{tabular}{|c|c|c|c|c|c|}
\hline Species & Number animals & $\begin{array}{l}\text { Caloric } \\
\text { restriction }\end{array}$ & Tissue & Outcome & Reference \\
\hline $\begin{array}{l}\text { Mice } \\
\text { (C57BL6) }\end{array}$ & 10 & $40 \%$ & $\begin{array}{l}\text { Muscle, fat } \\
\text { liver }\end{array}$ & $\begin{array}{l}\text { Sirtl } \uparrow \\
\text { (protein) } \\
\text { Sirt1 } \downarrow \\
\text { (protein) }\end{array}$ & {$[66]$} \\
\hline $\begin{array}{l}\text { Mice } \\
\text { (C57BL/6×C3H/He F1 } \\
\text { hybrid) }\end{array}$ & 4 & $15 \%$ & $\begin{array}{l}\text { Brain, liver } \\
\text { heart, muscle }\end{array}$ & $\begin{array}{l}\text { No effect on Sirtl } \\
\text { (protein) } \\
\text { Sirt1 } \downarrow \\
\text { (protein) }\end{array}$ & [13] \\
\hline $\begin{array}{l}\text { Mice } \\
\text { (C57BL6) }\end{array}$ & - & 24 h starvation & Liver & $\begin{array}{l}\text { Sirt } \uparrow \\
\text { (protein) } \\
\text { no effect on mRNA }\end{array}$ & {$[65]$} \\
\hline $\begin{array}{l}\text { Mice } \\
(\mathrm{C} 57 \mathrm{BL})\end{array}$ & - & $24 \mathrm{~h}$ starvation & $\begin{array}{l}\text { Brain, heart, } \\
\text { muscle, white } \\
\text { adipose tissue, and } \\
\text { kidney }\end{array}$ & $\begin{array}{l}\text { Sirtl } \uparrow \\
\text { (protein) } \\
\text { no effect on mRNA }\end{array}$ & {$[70]$} \\
\hline $\begin{array}{l}\text { Mice } \\
\text { (C57BLK/6×SV127 F1 } \\
\text { hybrid) }\end{array}$ & 10 & $30-40 \%$ & White adipose tissue & $\begin{array}{l}\text { Sirtl } \uparrow \\
\text { (protein) }\end{array}$ & [36] \\
\hline $\begin{array}{l}\text { Mice } \\
\text { (C57BL6) }\end{array}$ & - & $40 \%$ & $\begin{array}{l}\text { White adipose tissue, } \\
\text { liver, kidney, and } \\
\text { brain }\end{array}$ & $\begin{array}{l}\text { Sirt1 } \uparrow \\
\text { (protein) } \\
\text { not significant }\end{array}$ & {$[71]$} \\
\hline $\begin{array}{l}\text { Rats } \\
\text { (Fisher 344) }\end{array}$ & - & $40 \%$ & $\begin{array}{l}\text { Brain, fat, kidney, } \\
\text { and liver }\end{array}$ & $\begin{array}{l}\text { Sirtl } \uparrow \\
\text { (protein) }\end{array}$ & {$[57]$} \\
\hline
\end{tabular}

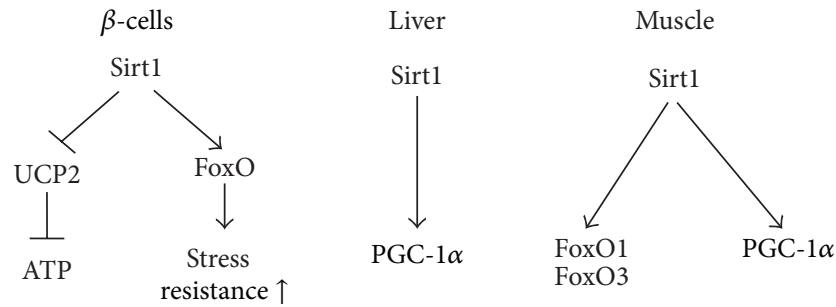

$$
\text { Insulin secretion } \uparrow \quad \begin{gathered}
\text { Gluconeogenesis } \uparrow \\
\text { Fatty acid oxidation } \uparrow
\end{gathered} \quad \begin{gathered}
\text { Mitochondria } \uparrow \\
\text { Metabolism } \uparrow
\end{gathered}
$$

FIGURE 1: Sirtl-mediated regulation of metabolism in different tissues according to [92]. In pancreatic $\beta$-cells Sirtl represses the expression of UCP2, thereby increasing insulin secretion, and Sirt 1 also regulates FoxOs, thereby protecting the $\beta$-cells against oxidative stress. In the liver Sirtl regulates gluconeogenesis by activating PGC- $1 \alpha$. In muscle cells Sirtl activates both PGC- $1 \alpha$ and FoxO, thereby influencing mitochondrial biogenesis, respiration, and fatty acid oxidation. ATP: adenosine triphosphate; FoxO: forkhead box protein $\mathrm{O}$; PGC-1 $\alpha$ : peroxisome proliferator-activated receptor- $\gamma$ coactivator 1 alpha; UCP: uncoupling protein 2.

been shown that Sirtl activation shifts metabolisms away from using glucose as an energy source. While Sirtl led to PPAR $\gamma$ inhibition, PPAR $\alpha$ that transcribes genes involved in fatty acid oxidation was activated by Sirtl localizing to PPAR response elements upon CR [67]. Additionally, deacetylation of PGC- $1 \alpha$ by Sirtl seems to lead to an activation of gluconeogenic gene transcription, while the expression of genes involved in glycolysis decreased [65]. With CR, PGC$1 \alpha$ is also induced on a transcriptional level and activated by
AMPK-mediated phosphorylation [68]. Activated PGC-1 $\alpha$ increases mitochondrial biogenesis by expressing several components of the respiratory chain. Moreover, PGC- $1 \alpha$ contributes to the metabolic shift away from glycolysis under conditions of limited nutrient supply by promoting mitochondrial fatty acid oxidation and gluconeogenesis in the liver [69].

However, while various reports find increased Sirtl protein levels in the muscle and WAT of CR animals, there is contradicting data as to whether liver Sirtl changes upon CR (see Table 3). Chen and colleagues [66] even stated that hepatic Sirtl levels were decreased by CR. This may be related to tissue-specific functions of Sirtl (Figure 1). In the study by Chen and colleagues, the repression of hepatic Sirtl by $\mathrm{CR}$ resulted in decreased hepatic fat synthesis and fat accumulation. Consistent with this finding, mice with a liverspecific knockout of Sirtl fed a Western diet showed lower body weight gain than wild type mice. A possible explanation for this lowered fat accumulation in the liver may be a reduced coactivation of liver $\mathrm{X}$ receptor (LXR) resulting in decreased activation of the cholesterol transporter ABCA1 and the fat synthesis regulator SREBP1c [66]. However, in another study also using Sirt1 LKO contrary observations were made, and a weight gain in the LKO mice higher than in the wild type controls was reported [67]. As pointed out by Haigis and Sinclair [72], this may have resulted from the different types of diets used in these two studies, with the diet from the second trial containing more fat. Of interest, transgenic Sirtl mice were protected against fatty liver when fed a high fat diet. Moreover, these mice showed lower $\mathrm{NF} \kappa \mathrm{B}$ activation and, consistently, lower levels of proinflammatory cytokines 


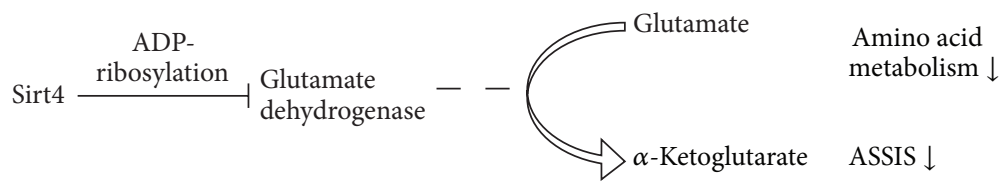

FIGURE 2: Sirt4 mediated amino acid metabolism according to [92]. ASSIS: amino acid-stimulated insulin secretion.

as well as lower glucose levels when compared to their wild type controls [73]. Thus, the authors hypothesize that Sirt1 protects from damage induced by a high fat diet.

3.2. Cardiovascular Disease and Sirt1. CVD is the primary cause of death in most countries and is characterized by elevated levels of low density lipoprotein cholesterol, oxidative damage to proteins and lipids and chronic inflammation. This environment promotes atherosclerotic plaque formation and a deteriorated endothelial function. Apart from genetic factors, a high fat diet and ageing are the main risk factors for developing this type of disease. Sirtl induction by CR or by the "sirtfood"- constituent resveratrol has been shown to counteract elevated levels of inflammation and might lower cholesterol and triglyceride synthesis [74]. An important factor that contributes to the protective role of Sirtl in CVD seems to be its function as a suppressor of the proinflammatory transcription factor $\mathrm{NF} \kappa \mathrm{B}$. Sirtl inhibits $\mathrm{NF} \kappa \mathrm{B}$-mediated transcription by deacetylating its subunit RelA/p65 and as a consequence lowering its DNA-binding ability [46]. Various reports have shown that Sirtl activation in vitro decreased the levels of proinflammatory mediators such as the tumour necrosis factor $\alpha$, interleukins 1 and 6, intercellular adhesion molecule 1, and inducible nitric oxide synthase (NOS) [72]. In a mouse model for CVD, an apolipoprotein E double knockout, and endothelial Sirtl overexpression lowered the formation of atherosclerotic plaques [75]. In mouse liver, it could be shown that Sirtl interacts with the nuclear factor LXR and activates this transcription factor through its deacetylation. LXR induces reverse cholesterol transport by activating the transcription of the cholesterol efflux transporter ABCA1, thereby lowering peripheral cholesterol levels and promoting cholesterol excretion [76]. In contrast to inducible NOS which is found in macrophages and produces NO that harms microorganisms, endothelial NOS (eNOS) protects arteries. Interestingly, it was shown that Sirtl activates eNOS and thus leads to endothelium-dependent vasodilatation.

3.3. Sirt1 Interaction with $A M P K$ and Importance for Autophagy. Activation of the energy sensing kinase AMPK has shown similar effects on metabolism energy expenditure as compared to sirtuin signalling on various occasions [77]. This can be explained by the findings that Sirtl activates AMPK [78] and vice versa [79]. Additionally, these reports point to the notion that both enzymes are needed to orchestrate the organism's response to limited nutrient supply or elevated energy demand during exercise. A part of the organism's response to such catabolic metabolic states is the lysosomal degradation pathway autophagy. Interestingly, autophagy was shown to be induced via Sirtl and AMPK [80, 81]. In Caenorhabditis elegans, autophagy induction is necessary for and contributes to the lifespan prolonging effect of $\mathrm{CR}$ and its mimetic resveratrol [82]. In another experiment measuring lifespan extension, autophagy deficient worms did not benefit from caloric restriction to the same extent as wild type C. elegans [83]. Similarly to the activation of sirtuins, autophagy induction leads to lifespan extension in Drosophila and other organisms $[84,85]$. In addition, sirtuins and autophagy are induced by CR [29]. Therefore, part of the ageing-related benefits from Sirtl activation by $\mathrm{CR}$ or polyphenolic CR mimetics seems to be caused by autophagy [86]. In the case of the secondary plant metabolite resveratrol this connection could already be shown. By inducing autophagy via Sirtl activation, resveratrol promoted longevity in worms and flies [87]. Interestingly, other polyphenolic Sirtl inducers such as quercetin also promoted autophagic degradation [15, 88]. Considering that autophagy is a starvation and especially in higher eukaryotes a stress response, the activation of this lysosomal degradation pathway might be one the main mechanisms by which Sirtl protects the organism from stressors (and thereby contributes to longevity).

3.4. The Mammalian Sirtuins 2-6. Apart from Sirt1, both Sirt3 and Sirt4 play important metabolic roles during food limitation. Additionally, in a study by Kawahara and coworkers [89], Sirt6-induced histone deacetylation led to prolongation of lifespan.

Sirt3 is mainly expressed in the liver, kidney, brain, and brown adipose tissue [90]. A high expression of Sirt3 in brown adipose tissue during $\mathrm{CR}$ induces the expression of PGC- $1 \alpha$ and the uncoupling protein-1 (UCP-1) which is important for thermogenesis. Downregulation of Sirt 4 by CR seems to affect amino acid metabolism and insulin secretion. Decreased Sirt4 levels lead to a higher conversion of glutamate to $\alpha$-ketoglutarate by the glutamate dehydrogenase GDH [91], thereby promoting the use of amino acids as ATP source under CR. Contrarily, under nutrient-rich conditions Sirt4 ADP-ribosylates GDH which attenuates GDH activity [91]. Furthermore, CR-mediated Sirt4 decrease and GDH activity induce the amino acid-stimulated insulin secretion (AASIS) resulting in increased insulin secretion in response to CR [92] (Figure 2).

\section{Potential Health Benefits of a MediterrAsian Diet}

As in the Western world the prevalence of obesity and ageassociated diseases such as type 2 diabetes mellitus, cancer, Alzheimer's, and atherosclerosis is increasing, and in order to 
benefit from CR a lifelong restriction seems to be necessary [41], interest in dietary restriction mimetics has been rising (see Table 4).

However, although substances such as metformin can be used as an antidiabetic drug [97], most of the pharmacological CR mimetics have severe side effects. Therefore, the consumption of secondary plant bioactives such as polyphenols with the normal diet appears to be a safer strategy to benefit from potentially healthspan-improving CR mimetics.

Although further studies are needed to prove that these foods promote health in humans through their CRmimicking secondary plant metabolite content, we hypothesize that the concept of combining foods from Asian and Mediterranean diets could possibly improve health status in an ageing population. Unfortunately, it can be difficult to study how dietary components influence health because of the low doses of bioactives found in diets when compared to the doses fed in some animal studies or the doses applied in most cell culture models. Additionally, bioactives are metabolised before and after adsorption from the gastrointestinal tract and could work synergistically or antagonistically with each other and other components in the diet. These factors make it complicated to extrapolate findings from in vitro and in vivo experiments to humans. Furthermore, when carrying out human studies, dietary effects tend to be smaller than in many pharmacological intervention studies and therefore require a higher number of participants to obtain measurable results. However, it seems that diets rich in saturated fats and cholesterol, low in fibre, and high in sugar and salt may increase CVD risk [1-3], and dietary factors such as olive oil consumption in the Mediterranean area [10] or seaweed in coastal Asia [11] may decrease CVD risk. Therefore, we believe that combining Asian and Mediterranean foods in a MediterrAsian diet could be a promising approach for improving human health.

4.1. Components of Mediterranean Diets. From a nutritional point of view there is a substantial overlap between the Asian and Mediterranean diets. These diets are rich in fruit and especially vegetables which are both important sources of dietary polyphenols, glucosinolates, and vitamin $\mathrm{C}$ (see Figure 3). Furthermore, for some parts of Asia and the Mediterranean a high consumption of oily fish rich in omega 3 fatty acids has been reported. Consistent with the low incidence of CVD in populations consuming such diets in Asia and the Mediterranean area, it has been suggested that foods with a high content of polyphenols, glucosinolates, and omega 3 fatty acids reduce the CVD risk.

In addition, there are also specific foods which are predominantly consumed in the Mediterranean area such as red wine. The same is true for olive oil which is also consumed to a higher extent in Southern as opposed to Northern Europe. Studies in model organisms (e.g., C. elegans, D. melanogaster), and laboratory rodents suggest that red wine constituents (e.g., resveratrol) may positively affect both health and lifespan [14, 16]. Our own data demonstrate that mice consuming diets rich in olive oil phenolics (e.g., hydroxytyrosol) exhibit decreased oxidative damage markers (e.g., lipid peroxides, protein carbonyls) and improved expression of Nrf2-dependent genes encoding antioxidant ( $\gamma$ GCS, NQO1) and cardioprotective (paraoxonase) proteins. We have also shown that olive oil phenolics may induce proteasomal activity and Sirtl signalling [98]. Recently, another group also observed Sirtl induction by olive oil phenolics [99], and further evidence exists supporting a role of polyphenols in gene regulation via sirtuins and transcription factors such as $\mathrm{Nrf} 2$ and $\mathrm{NF} \kappa \mathrm{B}$ [17]. Resveratrol activated Nrf2 and attenuated oxidative stress, thereby protecting the endothelium in a mouse model [100] and inhibited inflammation in macrophages via downregulation of the proinflammatory $\mathrm{NF} \kappa \mathrm{B}$ [101]. Resveratrol has been repeatedly shown to induce Sirt1 $[15,82,102]$, and therefore it seems possible that the endothelium protection and $\mathrm{NF} \kappa \mathrm{B}$ inhibition may also be connected to Sirtl induction. The polyphenol quercetin found in onions could also induce Sirtl [15]. In Table 5, we have listed polyphenols that were shown to induce sirtuins and the type of foods they are found in. Given the fact that Sirtl activation appears to benefit health by mimicking CR, these "sirtfoods" may contribute to healthy ageing.

4.2. Components of Asian Diets. The Asian diet is rich in soy and turmeric. Curcuma longa is a significant source of curcumin [111], and soy contains considerable amounts of isoflavones $[112,113]$. Similar to resveratrol and quercetin, curcumin has also been shown to induce Nrf2 [114] and other transcription factors [115] and inhibit NF $\kappa \mathrm{B}$-mediated inflammation [116, 117]. In contrast to the Asian diet, the Mediterranean diet is almost devoid of both isoflavones and curcumin. We and others have shown that soy isoflavones and curcumin mediates cardioprotective activity including reduction of LDL oxidation, inhibition of platelet aggregation, and improvement in vascular reactivity [118-120]. Interestingly, isoflavones such as daidzein were also shown to induce Sirtl and PGC- $1 \alpha$ [103]. Further constituents of the Asian diet that contain possible health-promoting bioactives are green tea and seaweed. Tea polyphenols seem to inhibit the proinflammatory transcription factor $\mathrm{NF} \kappa \mathrm{B}$ [121], while seaweed is a source of antioxidant vitamins and polyunsaturated omega 3 fatty acids [122] which may also prevent CVD $[123,124]$.

\subsection{Human Intervention Studies on Secondary Plant Metabo-} lites Found in the MediterrAsian Diet. Most of the in vitro and in vivo research and various human intervention studies with bioactives from the Mediterranean and Asian diets found promising results regarding possible health-promoting benefits $[125,126]$. However, some studies reported controversial data. For example, red wine has been stated to decrease low density lipoprotein (LDL) peroxidation in humans which would be beneficial for CVD prevention [127]. In contrast, red or white wine with a reduced alcohol content did not decrease (LDL) peroxidation in human volunteers [128], and one group of researchers showed that although moderate red wine consumption could lower LDL oxidation, the other tested alcoholic beverages also did [129]. On the other hand, in one study only red wine as compared to white wine 


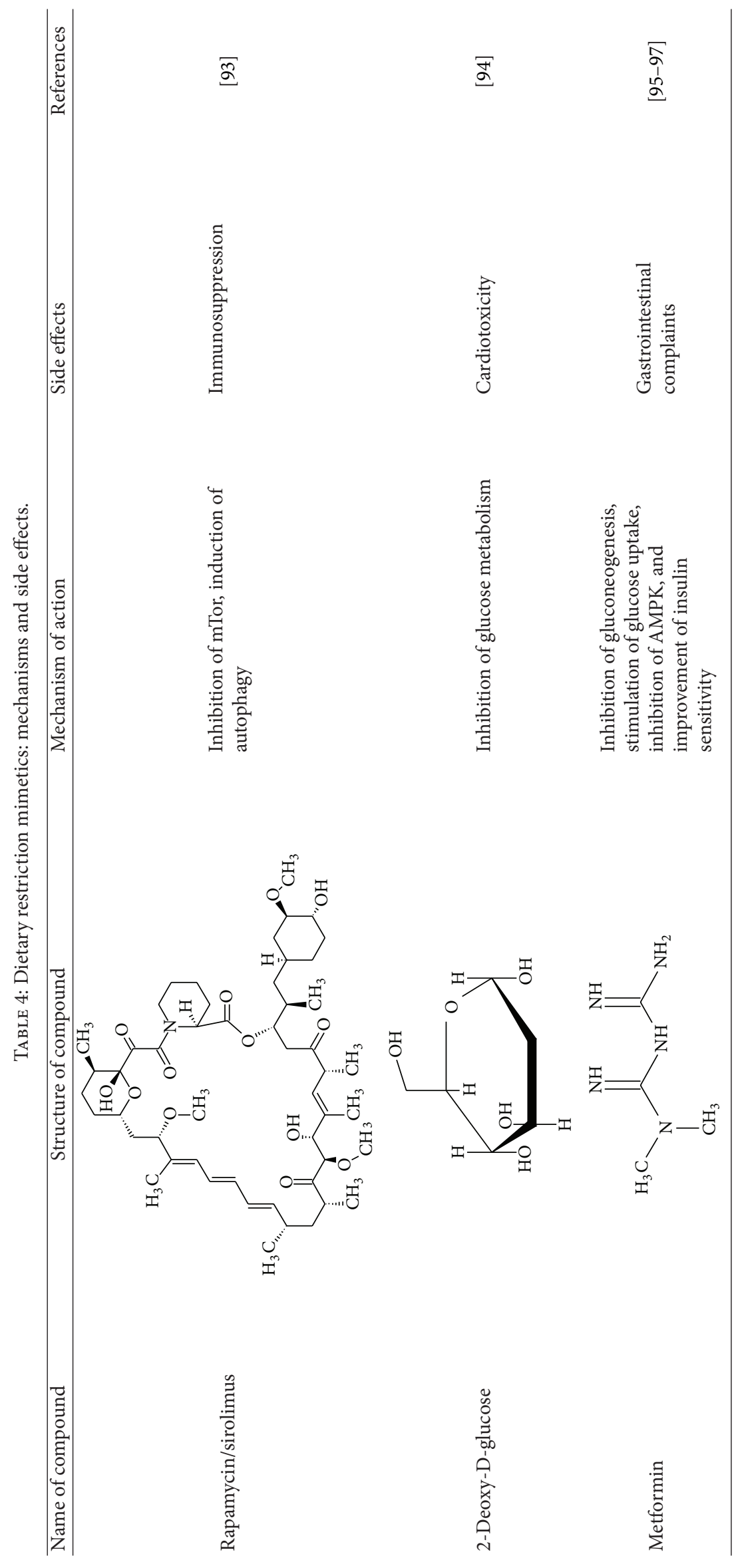




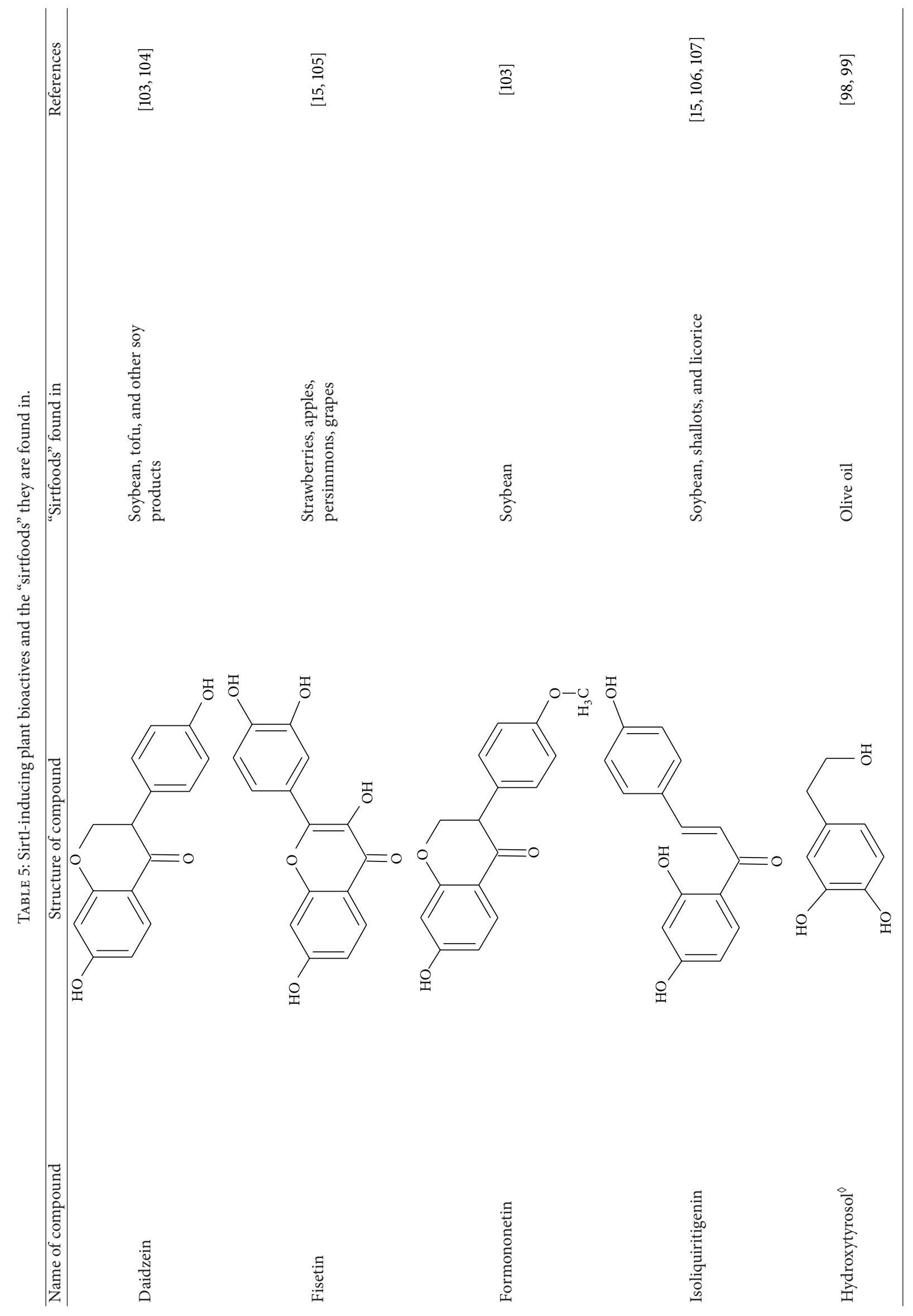




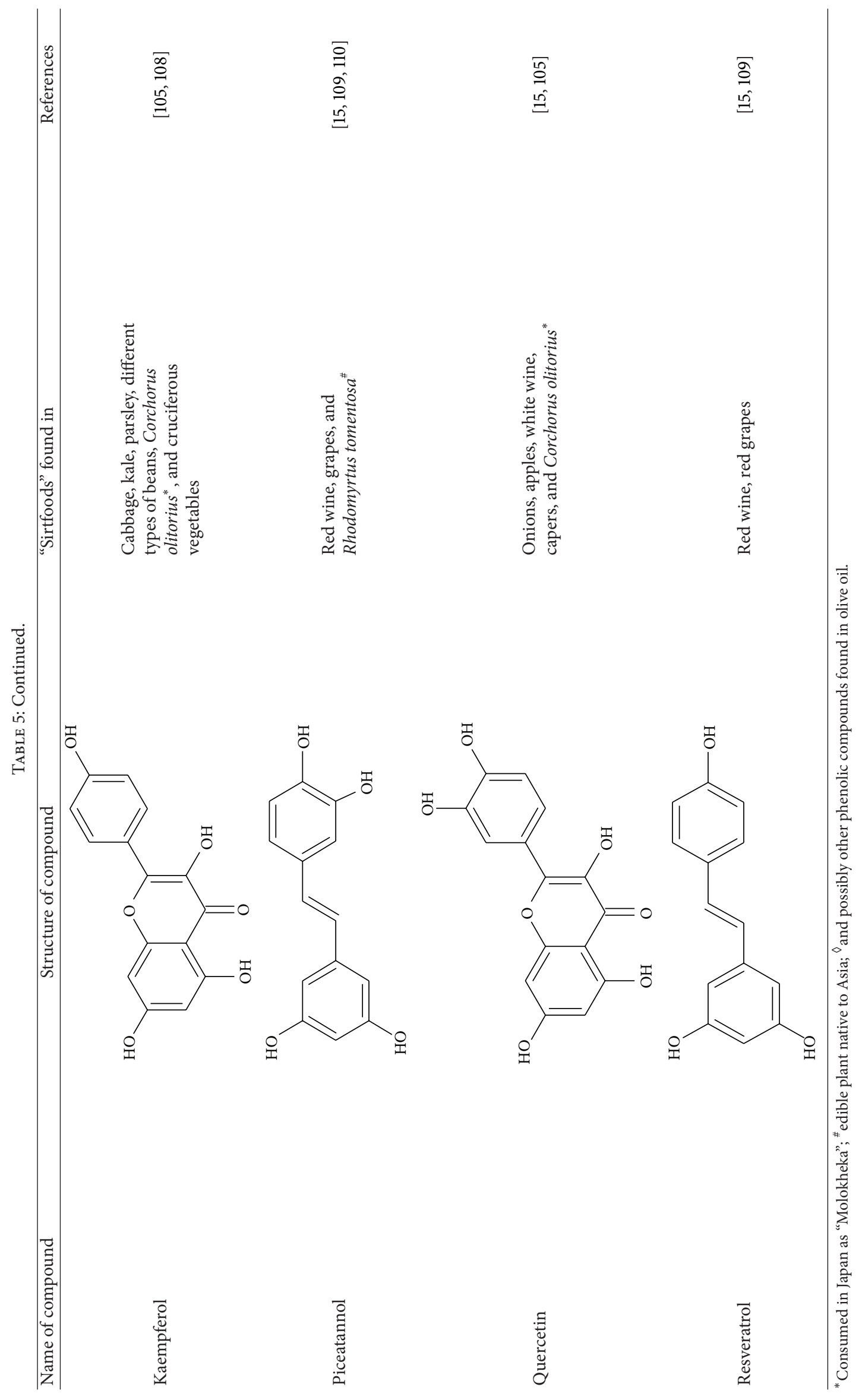




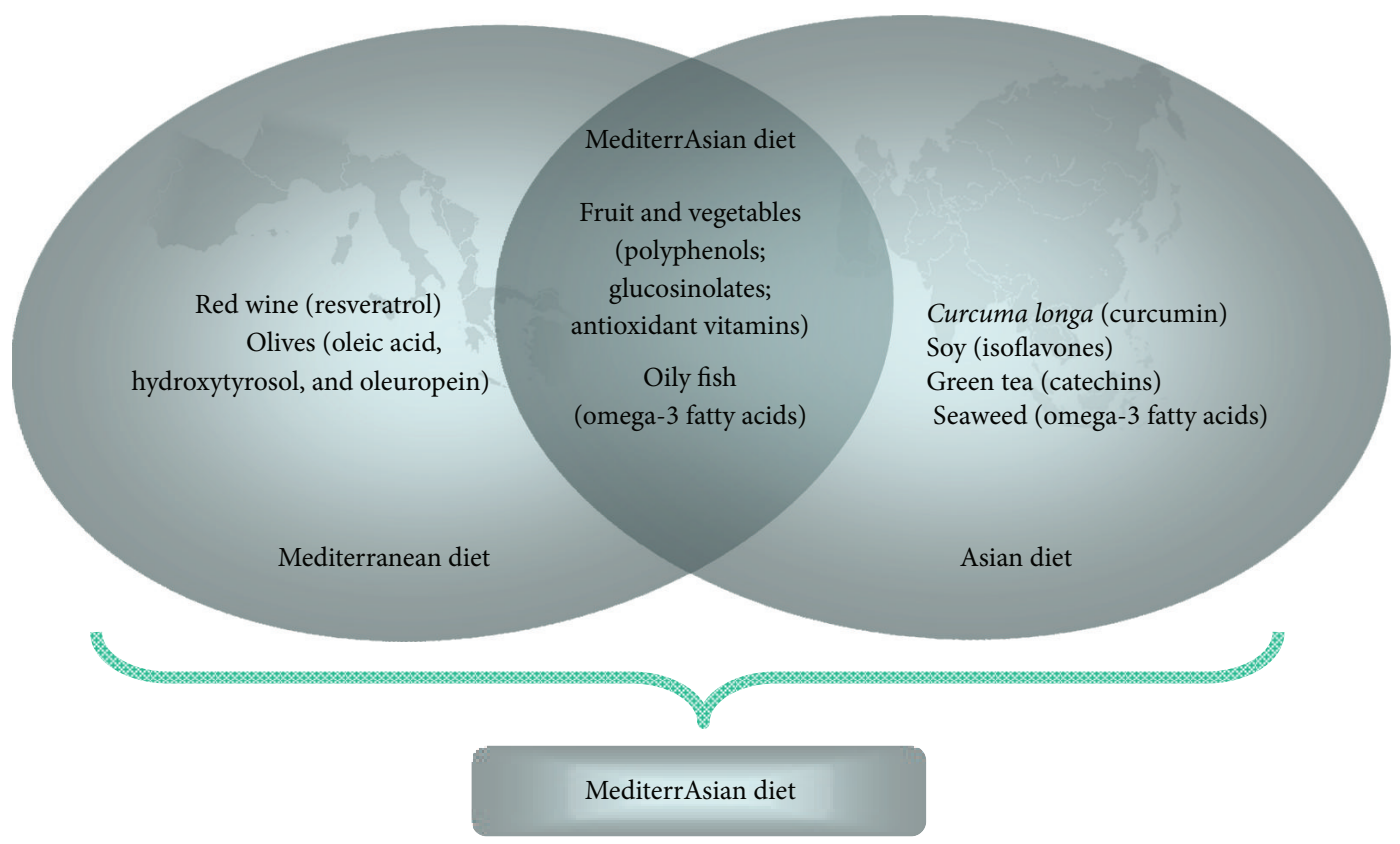

FIGURE 3: Important food items and their corresponding constituents in the Mediterranean, Asian, and so-called MediterrAsian diet.

lowered LDL oxidation in healthy humans, thereby pointing to the notion that certain components found in red but not white wine are responsible for this effect [130]. Similarly conflicting results were reported for the influence of fruitderived polyphenols on blood pressure. While Aviram and colleagues observed that pomegranate juice reduced blood pressure in humans [131], in the study by Sumner and colleagues blood pressure did not change after administering pomegranate juice to the patients [132]. In the context of cancer prevention by soy-containing diets, a meta-analysis on the influence of isoflavones on a breast cancer biomarker found only a small positive effect that might or might not be clinically relevant [133]. In the case of curcumin, data from cell models and animal studies made this polyphenol appear an efficient treatment for dementia [134]. However, in clinical trials curcumin did not improve the symptoms of Alzheimer patients [135]. There are various factors that may contribute or explain these controversial findings including the differences in the health status of the patients, different doses and dosage forms, or different parameters measured (e.g., lipid peroxidation in plasma versus blood pressure for CVD). However, these conflicting results demonstrate that further research is needed to better understand the effect of dietary components on sirtuin activation and healthy ageing.

\section{Conclusion}

A high content of fruit, vegetables, and oily fish in the diets of Mediterranean and certain Asian populations is likely to cause the improved health status observed in the MediterrAsian area.

However, we suggest that plant bioactives, antioxidant vitamins, and omega-3 fatty acids do not work in isolation. Rather they may act synergistically, thereby preventing chronic diseases. Thus, it is possible that the complex mixture of diet-derived plant bioactives, antioxidatives, and omega3 fatty acids cannot be substituted by a single purified compound [136].

Instead we propose combining healthy foodstuffs of the Asian and the Mediterranean diets especially rich in "sirtfoods" in order to prevent chronic diseases and ensure healthy ageing.

We would like to encourage future studies in cultured cells, model organisms, laboratory rodents, and ultimately humans to unravel and evaluate potential health benefits of the MediterrAsian diet from a molecular to the system biology level.

\section{References}

[1] N. J. Aburto, A. Ziolkovska, L. Hooper, P. Elliott, F. P. Cappuccio, and J. J. Meerpohl, "Effect of lower sodium intake on health: systematic review and meta-analyses," British Medical Journal, vol. 346, Article ID f1326, 2013.

[2] W. C. Willett, "Dietary fats and coronary heart disease," Journal of Internal Medicine, vol. 272, no. 1, pp. 13-24, 2012.

[3] F. J. Sanchez-Muniz, "Dietary fibre and cardiovascular health," Nutricion Hospitalaria, vol. 27, no. 1, pp. 31-45, 2012.

[4] M. Kon and A. M. Cuervo, "Chaperone-mediated autophagy in health and disease," FEBS Letters, vol. 584, no. 7, pp. 1399-1404, 2010.

[5] R. J. Colman, R. M. Anderson, S. C. Johnson et al., "Caloric restriction delays disease onset and mortality in rhesus monkeys," Science, vol. 325, no. 5937, pp. 201-204, 2009.

[6] R. Weindruch and R. L. Walford, "Dietary restriction in mice beginning at 1 year of age: effect on life-span and spontaneous cancer incidence," Science, vol. 215, no. 4538, pp. 1415-1418, 1982. 
[7] J. A. Mattison, G. S. Roth, T. M. Beasley et al., "Impact of caloric restriction on health and survival in rhesus monkeys from the NIA study," Nature, vol. 489, no. 7415, pp. 318-321, 2012.

[8] D. Vauzour, A. Rodriguez-Mateos, G. Corona, M. J. OrunaConcha, and J. P. E. Spencer, "Polyphenols and human health: prevention of disease and mechanisms of action," Nutrients, vol. 2, no. 11, pp. 1106-1131, 2010.

[9] D. Vauzour, "Dietary polyphenols as modulators of brain functions: biological actions and molecular mechanisms underpinning their beneficial effects," Oxidative Medicine and Cellular Longevity, vol. 2012, Article ID 914273, 16 pages, 2012.

[10] G. Buckland, N. Travier, A. Barricarte et al., "Olive oil intake and $\mathrm{CHD}$ in the European Prospective Investigation into Cancer and Nutrition Spanish cohort," The British Journal of Nutrition, vol. 108, no. 11, pp. 2075-2082, 2012.

[11] A. Bocanegra, S. Bastida, J. Benedí, S. Ródenas, and F. J. Sánchez-Muniz, "Characteristics and nutritional and cardiovascular-health properties of seaweeds," Journal of Medicinal Food, vol. 12, no. 2, pp. 236-258, 2009.

[12] S. Timmers, E. Konings, L. Bilet et al., "Calorie restrictionlike effects of 30 days of resveratrol supplementation on energy metabolism and metabolic profile in obese humans," Cell Metabolism, vol. 14, no. 5, pp. 612-622, 2011.

[13] J. L. Barger, T. Kayo, J. M. Vann et al., "A low dose of dietary resveratrol partially mimics caloric restriction and retards aging parameters in mice," PLoS ONE, vol. 3, no. 6, Article ID e2264, 2008.

[14] J. A. Baur, K. J. Pearson, N. L. Price et al., "Resveratrol improves health and survival of mice on a high-calorie diet," Nature, vol. 444, no. 7117, pp. 337-342, 2006.

[15] K. T. Howitz, K. J. Bitterman, H. Y. Cohen et al., "Small molecule activators of sirtuins extend Saccharomyces cerevisiae lifespan," Nature, vol. 425, no. 6954, pp. 191-196, 2003.

[16] J. G. Wood, B. Rogina, S. Lavu et al., "Sirtuin activators mimic caloric restriction and delay ageing in metazoans," Nature, vol. 430, no. 7000, pp. 686-689, 2004.

[17] S. Chung, H. Yao, S. Caito, J. Hwang, G. Arunachalam, and I. Rahman, "Regulation of SIRT1 in cellular functions: role of polyphenols," Archives of Biochemistry and Biophysics, vol. 501, no. 1, pp. 79-90, 2010.

[18] J. R. Speakman and S. E. Mitchell, "Caloric restriction," Molecular Aspects of Medicine, vol. 32, no. 3, pp. 159-221, 2011.

[19] I. Hochberg and Z. Hochberg, "Hypothalamic obesity," Endocrine Development, vol. 17, pp. 185-196, 2009.

[20] J. M. Friedman and J. L. Halaas, "Leptin and the regulation of body weight in mammals," Nature, vol. 395, no. 6704, pp. 763$770,1998$.

[21] F. Ziemke and C. S. Mantzoros, "Adiponectin in insulin resistance: lessons from translational research," American Journal of Clinical Nutrition, vol. 91, no. 1, pp. 258S-261S, 2010.

[22] D. P. Argentino, M. C. Muñoz, J. S. Rocha, A. Bartke, D. Turyn, and F. P. Dominici, "Short-term caloric restriction does not modify the in vivo insulin signaling pathway leading to Akt activation in skeletal muscle of Ames dwarf (Propldf/Propldf) mice," Hormone and Metabolic Research, vol. 37, no. 11, pp. 672679, 2005.

[23] H. M. Brown-Borg, K. E. Borg, C. J. Meliska, and A. Bartke, "Dwarf mice and the ageing process," Nature, vol. 384, no. 6604, p. 33, 1996.

[24] N. Libina, J. R. Berman, and C. Kenyon, "Tissue-Specific Activities of C. elegans DAF-16 in the regulation of lifespan," Cell, vol. 115, no. 4, pp. 489-502, 2003.
[25] S. Wullschleger, R. Loewith, and M. N. Hall, “TOR signaling in growth and metabolism," Cell, vol. 124, no. 3, pp. 471-484, 2006.

[26] B. Viollet, B. Guigas, J. Leclerc et al., "AMP-activated protein kinase in the regulation of hepatic energy metabolism: from physiology to therapeutic perspectives," Acta Physiologica, vol. 196, no. 1, pp. 81-98, 2009.

[27] W. Yen and D. J. Klionsky, "How to live long and prosper: autophagy, mitochondria, and aging," Physiology, vol. 23, no. 5, pp. 248-262, 2008.

[28] B. Levine and G. Kroemer, "Autophagy in the pathogenesis of disease," Cell, vol. 132, no. 1, pp. 27-42, 2008.

[29] A. M. Cuervo, E. Bergamini, U. T. Brunk, W. Dröge, M. Ffrench, and A. Terman, "Autophagy and aging: the importance of maintaining "clean" cells," Autophagy, vol. 1, no. 3, pp. 131-140, 2005.

[30] B. P. Yu, "Aging and oxidative stress: modulation by dietary restriction," Free Radical Biology and Medicine, vol. 21, no. 5, pp. 651-668, 1996.

[31] V. I. Pérez, A. Bokov, H. V. Remmen et al., "Is the oxidative stress theory of aging dead?" Biochimica et Biophysica Acta, vol. 1790, no. 10, pp. 1005-1014, 2009.

[32] R. S. Sohal and R. Weindruch, "Oxidative stress, caloric restriction, and aging," Science, vol. 273, no. 5271, pp. 59-63, 1996.

[33] K. Houthoofd, B. P. Braeckman, I. Lenaerts et al., "No reduction of metabolic rate in food restricted Caenorhabditis elegans," Experimental gerontology, vol. 37, no. 12, pp. 1359-1369, 2002.

[34] M. P. Mattson, "Hormesis defined," Ageing Research Reviews, vol. 7, no. 1, pp. 1-7, 2008.

[35] T. J. Schulz, K. Zarse, A. Voigt, N. Urban, M. Birringer, and M. Ristow, "Glucose restriction extends caenorhabditis elegans life span by inducing mitochondrial respiration and increasing oxidative stress," Cell Metabolism, vol. 6, no. 4, pp. 280-293, 2007.

[36] E. Nisoli, C. Tonello, A. Cardile et al., "Cell biology: calorie restriction promotes mitochondrial biogenesis by inducing the expression of eNOS," Science, vol. 310, no. 5746, pp. 314-317, 2005.

[37] R. Venugopal and A. K. Jaiswal, "Nrf1 and Nrf2 positively and c-Fos and Fral negatively regulate the human antioxidant response element-mediated expression of NAD $(\mathrm{P}) \mathrm{H}$ :quinone oxidoreductasel gene," Proceedings of the National Academy of Sciences of the United States of America, vol. 93, no. 25, pp. 14960-14965, 1996.

[38] T. H. Rushmore and C. B. Pickett, “Transcriptional regulation of the rat glutathione S-transferase Ya subunit gene. Characterization of a xenobiotic-responsive element controlling inducible expression by phenolic antioxidants," The Journal of Biological Chemistry, vol. 265, no. 24, pp. 14648-14653, 1990.

[39] T. Nguyen, P. Nioi, and C. B. Pickett, "The Nrf2-antioxidant response element signaling pathway and its activation by oxidative stress," The Journal of Biological Chemistry, vol. 284, no. 20, pp. 13291-13295, 2009.

[40] E. Xia, G. Rao, H. Van Remmen, A. R. Heydari, and A. Richardson, "Activities of antioxidant enzymes in various tissues of male Fischer 344 rats are altered by food restriction," Journal of Nutrition, vol. 125, no. 2, pp. 195-201, 1995.

[41] K. Giller, P. Huebbe, S. Hennig et al., "Beneficial effects of a 6-month dietary restriction are time-dependently abolished within 2 weeks or 6 months of refeeding-genome-wide transcriptome analysis in mouse liver," Free Radical Biology \& Medicine, vol. 61, pp. 170-178, 2013. 
[42] H. Y. Chung, B. Sung, K. J. Jung, Y. Zou, and B. P. Yu, “The molecular inflammatory process in aging," Antioxidants and Redox Signaling, vol. 8, no. 3-4, pp. 572-581, 2006.

[43] B. Chandrasekar, J. F. Nelson, J. T. Colston, and G. L. Freeman, "Calorie restriction attenuates inflammatory responses to myocardial ischemia-reperfusion injury," American Journal of Physiology, vol. 280, no. 5, pp. H2094-H2102, 2001.

[44] K. J. Jung, E. K. Lee, J. Y. Kim et al., "Effect of short term calorie restriction on pro-inflammatory NF- $\kappa \mathrm{B}$ and $\mathrm{AP}-1$ in aged rat kidney," Inflammation Research, vol. 58, no. 3, pp. 143-150, 2009.

[45] A. Csiszar, M. Wang, E. G. Lakatta, and Z. Ungvari, "Inflammation and endothelial dysfunction during aging: role of NF- $\kappa \mathrm{B}$," Journal of Applied Physiology, vol. 105, no. 4, pp. 1333-1341, 2008.

[46] F. Yeung, J. E. Hoberg, C. S. Ramsey et al., "Modulation of $\mathrm{NF}-\kappa \mathrm{B}$-dependent transcription and cell survival by the SIRT1 deacetylase," The EMBO Journal, vol. 23, no. 12, pp. 2369-2380, 2004.

[47] H. Kim, B. Yu, and H. Chung, "Molecular exploration of agerelated NF- $\kappa \mathrm{B} / \mathrm{IKK}$ downregulation by calorie restriction in rat kidney," Free Radical Biology and Medicine, vol. 32, no. 10, pp. 991-1005, 2002.

[48] D. A. Salih and A. Brunet, "FoxO transcription factors in the maintenance of cellular homeostasis during aging," Current Opinion in Cell Biology, vol. 20, no. 2, pp. 126-136, 2008.

[49] S. Ribaric, "Diet and aging," Oxidative Medicine and Cellular Longevity, vol. 2012, Article ID 741468, 20 pages, 2012.

[50] H. Yamaza, T. Komatsu, S. Wakita et al., "FoxO1 is involved in the antineoplastic effect of calorie restriction," Aging Cell, vol. 9, no. 3, pp. 372-382, 2010.

[51] F. Flachsbart, A. Caliebe, R. Kleindorp et al., "Association of FOX03A variation with human longevity confirmed in German centenarians," Proceedings of the National Academy of Sciences of the United States of America, vol. 106, no. 8, pp. 2700-2705, 2009.

[52] N. Hariharan, Y. Maejima, J. Nakae, J. Paik, R. A. Depinho, and J. Sadoshima, "Deacetylation of FoxO by Sirtl plays an essential role in mediating starvation-induced autophagy in cardiac myocytes," Circulation Research, vol. 107, no. 12, pp. 1470-1482, 2010.

[53] A. Brunet, L. B. Sweeney, J. F. Sturgill et al., "Stress-dependent regulation of FOXO transcription factors by the SIRT1 deacetylase," Science, vol. 303, no. 5666, pp. 2011-2015, 2004.

[54] M. C. Motta, N. Divecha, M. Lemieux et al., "Mammalian SIRT1 represses forkhead transcription factors," Cell, vol. 116, no. 4, pp. 551-563, 2004.

[55] H. Daitoku, M. Hatta, H. Matsuzaki et al., "Silent information regulator 2 potentiates Foxo 1-mediated transcription through its deacetylase activity," Proceedings of the National Academy of Sciences of the United States of America, vol. 101, no. 27, pp. 10042-10047, 2004.

[56] H. You and T. W. Mak, "Crosstalk between p53 and FOXO transcription factors," Cell Cycle, vol. 4, no. 1, pp. 37-38, 2005.

[57] H. Y. Cohen, C. Miller, K. J. Bitterman et al., "Calorie restriction promotes mammalian cell survival by inducing the SIRT1 deacetylase," Science, vol. 305, no. 5682, pp. 390-392, 2004.

[58] A. Van Der Horst, L. G. J. Tertoolen, L. M. M. De VriesSmits, R. A. Frye, R. H. Medema, and B. M. T. Burgering, "FOXO4 is acetylated upon peroxide stress and deacetylated by the longevity protein hSir2SIRT1," The Journal of Biological Chemistry, vol. 279, no. 28, pp. 28873-28879, 2004.
[59] S. Imai, C. M. Armstrong, M. Kaeberlein, and L. Guarente, "Transcriptional silencing and longevity protein Sir2 is an NAD-dependent histone deacetylase," Nature, vol. 403, no. 6771, pp. 795-800, 2000.

[60] C. Cantó and J. Auwerx, "Caloric restriction, SIRT1 and longevity," Trends in Endocrinology and Metabolism, vol. 20, no. 7, pp. 325-331, 2009.

[61] Y. Li, M. Daniel, and T. O. Tollefsbol, "Epigenetic regulation of caloric restriction in aging," BMC Medicine, vol. 9, article 98, 2011.

[62] M. Kaeberlein, M. McVey, and L. Guarente, "The SIR2/3/4 complex and SIR2 alone promote longevity in Saccharomyces cerevisiae by two different mechanisms," Genes and Development, vol. 13, no. 19, pp. 2570-2580, 1999.

[63] M. C. Haigis and L. P. Guarente, "Mammalian sirtuinsemerging roles in physiology, aging, and calorie restriction," Genes and Development, vol. 20, no. 21, pp. 2913-2921, 2006.

[64] F. Picard, M. Kurtev, N. Chung et al., "Sirtl promotes fat mobilization in white adipocytes by repressing PPAR- $\gamma$," Nature, vol. 429, no. 6993, pp. 771-776, 2004.

[65] J. T. Rodgers, C. Lerin, W. Haas, S. P. Gygi, B. M. Spiegelman, and P. Puigserver, "Nutrient control of glucose homeostasis through a complex of PGC-1 $\alpha$ and SIRT1," Nature, vol. 434, no. 7029, pp. 113-118, 2005.

[66] D. Chen, J. Bruno, E. Easlon et al., "Tissue-specific regulation of SIRT1 by calorie restriction," Genes and Development, vol. 22, no. 13, pp. 1753-1757, 2008.

[67] A. Purushotham, T. T. Schug, Q. Xu, S. Surapureddi, X. Guo, and X. Li, "Hepatocyte-specific deletion of SIRT1 alters fatty acid metabolism and results in hepatic steatosis and inflammation," Cell Metabolism, vol. 9, no. 4, pp. 327-338, 2009.

[68] J. C. Corton and H. M. Brown-Borg, "Peroxisome proliferatoractivated receptor $\gamma$ coactivator 1 in caloric restriction and other models of longevity," Journals of Gerontology A, vol. 60, no. 12, pp. 1494-1509, 2005.

[69] R. C. Scarpulla, "Metabolic control of mitochondrial biogenesis through the PGC-1 family regulatory network," Biochimica et Biophysica Acta, vol. 1813, no. 7, pp. 1269-1278, 2011.

[70] Y. Kanfi, R. Shalman, V. Peshti et al., "Regulation of SIRT6 protein levels by nutrient availability," FEBS Letters, vol. 582, no. 5, pp. 543-548, 2008.

[71] F. Wang, M. Nguyen, F. X. Qin, and Q. Tong, "SIRT2 deacetylates FOXO3a in response to oxidative stress and caloric restriction," Aging Cell, vol. 6, no. 4, pp. 505-514, 2007.

[72] M. C. Haigis and D. A. Sinclair, "Mammalian sirtuins: biological insights and disease relevance," Annual Review of Pathology: Mechanisms of Disease, vol. 5, pp. 253-295, 2010.

[73] P. T. Pfluger, D. Herranz, S. Velasco-Miguel, M. Serrano, and M. H. Tschöp, "Sirtl protects against high-fat diet-induced metabolic damage," Proceedings of the National Academy of Sciences of the United States of America, vol. 105, no. 28, pp. 9793-9798, 2008.

[74] N. M. Borradaile and G. Pickering, "NAD+, sirtuins, and cardiovascular disease," Current Pharmaceutical Design, vol. 15, no. 1, pp. 110-117, 2009.

[75] Q. Zhang, Z. Wang, H. Chen et al., "Endothelium-specific overexpression of class III deacetylase SIRT1 decreases atherosclerosis in apolipoprotein E-deficient mice," Cardiovascular Research, vol. 80, no. 2, pp. 191-199, 2008.

[76] X. Li, S. Zhang, G. Blander, J. G. Tse, M. Krieger, and L. Guarente, "SIRT1 deacetylates and positively regulates the nuclear receptor LXR,” Molecular Cell, vol. 28, no. 1, pp. 91-106, 2007. 
[77] N. B. Ruderman, X. J. Xu, L. Nelson et al., "AMPK and SIRT1: a long-standing partnership?" American Journal of Physiology, vol. 298, no. 4, pp. E751-E760, 2010.

[78] X. Hou, S. Xu, K. A. Maitland-Toolan et al., "SIRT1 regulates hepatocyte lipid metabolism through activating AMP-activated protein kinase," The Journal of Biological Chemistry, vol. 283, no. 29, pp. 20015-20026, 2008.

[79] C. Cantó, L. Q. Jiang, A. S. Deshmukh et al., "Interdependence of AMPK and SIRT1 for metabolic adaptation to fasting and exercise in skeletal muscle," Cell Metabolism, vol. 11, no. 3, pp. 213-219, 2010.

[80] H. L. In, L. Cao, R. Mostoslavsky et al., "A role for the NADdependent deacetylase Sirtl in the regulation of autophagy," Proceedings of the National Academy of Sciences of the United States of America, vol. 105, no. 9, pp. 3374-3379, 2008.

[81] I. Papandreou, A. L. Lim, K. Laderoute, and N. C. Denko, "Hypoxia signals autophagy in tumor cells via AMPK activity, independent of HIF-1, BNIP3, and BNIP3L," Cell Death and Differentiation, vol. 15, no. 10, pp. 1572-1581, 2008.

[82] E. Morselli, M. C. Maiuri, M. Markaki et al., "Caloric restriction and resveratrol promote longevity through the Sirtuin-1dependent induction of autophagy," Cell Death and Disease, vol. 1, no. 1, article e10, 2010.

[83] M. Hansen, A. Chandra, L. L. Mitic, B. Onken, M. Driscoll, and C. Kenyon, "A role for autophagy in the extension of lifespan by dietary restriction in C. elegans," PLoS Genetics, vol. 4, no. 2, article e24, 2008.

[84] A. Simonsen, R. C. Cumming, A. Brech, P. Isakson, D. R. Schubert, and K. D. Finley, "Promoting basal levels of autophagy in the nervous system enhances longevity and oxidant resistance in adult Drosophila," Autophagy, vol. 4, no. 2, pp. 176-184, 2008.

[85] B. Rogina and S. L. Helfand, "Sir2 mediates longevity in the fly through a pathway related to calorie restriction," Proceedings of the National Academy of Sciences of the United States of America, vol. 101, no. 45, pp. 15998-16003, 2004.

[86] K. Pallauf and G. Rimbach, "Autophagy, polyphenols and healthy ageing," Ageing Research Reviews, vol. 12, no. 1, pp. 237252, 2013.

[87] E. Morselli, M. C. Maiuri, M. Markaki et al., "The life span-prolonging effect of sirtuin-1 is mediated by autophagy," Autophagy, vol. 6, no. 1, pp. 186-188, 2010.

[88] K. Wang, R. Liu, J. Li et al., "Quercetin induces protective autophagy in gastric cancer cells: involvement of Akt-mTORand hypoxia-induced factor $1 \alpha$-mediated signaling," Autophagy, vol. 7, no. 9, pp. 966-978, 2011.

[89] T. L. A. Kawahara, E. Michishita, A. S. Adler et al., "SIRT6 links histone $\mathrm{H} 3$ lysine 9 deacetylation to NF- $\kappa \mathrm{B}$-dependent gene expression and organismal life span," Cell, vol. 136, no. 1, pp. 6274, 2009.

[90] T. Shi, F. Wang, E. Stieren, and Q. Tong, "SIRT3, a mitochondrial sirtuin deacetylase, regulates mitochondrial function and thermogenesis in brown adipocytes," The Journal of Biological Chemistry, vol. 280, no. 14, pp. 13560-13567, 2005.

[91] M. C. Haigis, R. Mostoslavsky, K. M. Haigis et al., "SIRT4 inhibits glutamate dehydrogenase and opposes the effects of calorie restriction in pancreatic $\beta$ cells," Cell, vol. 126, no. 5, pp. 941-954, 2006.

[92] L. Guarente, "Sirtuins as potential targets for metabolic syndrome," Nature, vol. 444, no. 7121, pp. 868-874, 2006.

[93] I. Bjedov, J. M. Toivonen, F. Kerr et al., "Mechanisms of life span extension by rapamycin in the fruit fly drosophila melanogaster," Cell Metabolism, vol. 11, no. 1, pp. 35-46, 2010.
[94] D. K. Ingram and G. S. Roth, "Glycolytic inhibition as a strategy for developing calorie restriction mimetics," Experimental Gerontology, vol. 46, no. 2-3, pp. 148-154, 2011.

[95] I. B. Sahra, Y. L. Marchand-Brustel, J. Tanti, and F. Bost, "Metformin in cancer therapy: a new perspective for an old antidiabetic drug?" Molecular Cancer Therapeutics, vol. 9, no. 5, pp. 1092-1099, 2010.

[96] H. K. Park, "Metformin and cancer in type 2 diabetes," Diabetes \& Metabolism Journal, vol. 37, no. 2, pp. 113-116, 2013.

[97] C. Bouza, T. Lopez-Cuadrado, L. F. Gutierrez-Torres, and J. Amate, "Efficacy and safety of metformin for treatment of overweight and obesity in adolescents: an updated systematic review and meta-analysis," Obesity Facts, vol. 5, no. 5, pp. 753$765,2012$.

[98] B. Bayram, B. Ozcelik, S. Grimm et al., "A diet rich in olive oil phenolics reduces oxidative stress in the heart of SAMP8 mice by induction of Nrf2-dependent gene expression," Rejuvenation Research, vol. 15, no. 1, pp. 71-81, 2012.

[99] J. A. Menendez, J. Joven, G. Aragones et al., "Xenohormetic and anti-aging activity of secoiridoid polyphenols present in extra virgin olive oil: a new family of gerosuppressant agents," Cell Cycle, vol. 12, no. 4, pp. 555-578, 2013.

[100] Z. Ungvari, Z. Bagi, A. Feher et al., "Resveratrol confers endothelial protection via activation of the antioxidant transcription factor Nrf2," American Journal of Physiology, vol. 299, no. 1, pp. H18-H24, 2010.

[101] S. Tsai, S. Lin-Shiau, and J. Lin, "Suppression of nitric oxide synthase and the down-regulation of the activation of NF $\kappa \mathrm{B}$ in macrophages by resveratrol," British Journal of Pharmacology, vol. 126, no. 3, pp. 673-680, 1999.

[102] J. N. Feige, M. Lagouge, C. Canto et al., "Specific SIRT1 activation mimics low energy levels and protects against dietinduced metabolic disorders by enhancing fat oxidation," Cell Metabolism, vol. 8, no. 5, pp. 347-358, 2008.

[103] K. A. Rasbach and R. G. Schnellmann, "Isoflavones promote mitochondrial biogenesis," Journal of Pharmacology and Experimental Therapeutics, vol. 325, no. 2, pp. 536-543, 2008.

[104] T. Song, K. Barua, G. Buseman, and P. A. Murphy, "Soy isoflavone analysis: quality control and a new internal standard," American Journal of Clinical Nutrition, vol. 68, supplement 6, pp. 1474S-1479S, 1998.

[105] Y. Arai, S. Watanabe, M. Kimira, K. Shimoi, R. Mochizuki, and N. Kinae, "Dietary intakes of flavonols, flavones and isoflavones by Japanese women and the inverse correlation between quercetin intake and plasma LDL cholesterol concentration," Journal of Nutrition, vol. 130, no. 9, pp. 2243-2250, 2000.

[106] R. Kape, M. Parniske, S. Brandt, and D. Werner, "Isoliquiritigenin, a strong nod gene- and glyceollin resistance-inducing flavonoid from soybean root exudate," Applied and Environmental Microbiology, vol. 58, no. 5, pp. 1705-1710, 1992.

[107] Y. Hsu, C. Chia, P. Chen, S. Huang, S. Huang, and P. Kuo, "Shallot and licorice constituent isoliquiritigenin arrests cell cycle progression and induces apoptosis through the induction of ATM/p53 and initiation of the mitochondrial system in human cervical carcinoma HeLa cells," Molecular Nutrition and Food Research, vol. 53, no. 7, pp. 826-835, 2009.

[108] W. S. Da-Silva, J. W. Harney, B. W. Kim et al., "The small polyphenolic molecule kaempferol increases cellular energy expenditure and thyroid hormone activation," Diabetes, vol. 56, no. 3, pp. 767-776, 2007. 
[109] R. F. Guerrero, B. Puertas, M. I. Fernández, M. Palma, and E. Cantos-Villar, "Induction of stilbenes in grapes by UV-C: comparison of different subspecies of Vitis," Innovative Food Science and Emerging Technologies, vol. 11, no. 1, pp. 231-238, 2010.

[110] T. N. H. Lai, M. Herent -F, J. Quetin-Leclercq et al., "Piceatannol, a potent bioactive stilbene, as major phenolic component in Rhodomyrtus tomentosa," Food Chemistry, vol. 138, no. 2-3, pp. 1421-1430, 2013.

[111] A. Goel and B. B. Aggarwal, "Curcumin, the golden spice from Indian saffron, is a chemosensitizer and radiosensitizer for tumors and chemoprotector and radioprotector for normal organs," Nutrition and Cancer, vol. 62, no. 7, pp. 919-930, 2010.

[112] G. Rimbach, C. Boesch-Saadatmandi, J. Frank et al., "Dietary isoflavones in the prevention of cardiovascular disease-a molecular perspective," Food and Chemical Toxicology, vol. 46, no. 4, pp. 1308-1319, 2008.

[113] A. Mortensen, S. E. Kulling, H. Schwartz et al., "Analytical and compositional aspects of isoflavones in food and their biological effects," Molecular Nutrition and Food Research, vol. 53, supplement 2, pp. S266-S309, 2009.

[114] E. Balogun, M. Hoque, P. Gong et al., "Curcumin activates the haem oxygenase-1 gene via regulation of Nrf2 and the antioxidant-responsive element," Biochemical Journal, vol. 371, part 3, pp. 887-895, 2003.

[115] S. Shishodia, "Molecular mechanisms of curcumin action: gene expression," Biofactors, vol. 39, no. 1, pp. 37-55, 2013.

[116] C. Yeh, T. Chen, Y. Wu, Y. Lin, and P. Jing Lin, "Inhibition of $\mathrm{NF} \kappa \mathrm{B}$ activation with curcumin attenuates plasma inflammatory cytokines surge and cardiomyocytic apoptosis following cardiac ischemia/reperfusion," Journal of Surgical Research, vol. 125, no. 1, pp. 109-116, 2005.

[117] J. H. Kim, S. C. Gupta, B. Park, V. R. Yadav, and B. B. Aggarwal, "Turmeric (Curcuma longa) inhibits inflammatory nuclear factor (NF)- $\kappa \mathrm{B}$ and NF- $\kappa \mathrm{B}$-regulated gene products and induces death receptors leading to suppressed proliferation, induced chemosensitization, and suppressed osteoclastogenesis," Molecular Nutrition and Food Research, vol. 56, no. 3, pp. 454-465, 2012.

[118] G. Rimbach, P. D. Weinberg, S. De Pascual-Teresa et al., "Sulfation of genistein alters its antioxidant properties and its effect on platelet aggregation and monocyte and endothelial function," Biochimica et Biophysica Acta, vol. 1670, no. 3, pp. 229-237, 2004.

[119] R. Turner, T. Baron, S. Wolffram et al., "Effect of circulating forms of soy isoflavones on the oxidation of low density lipoprotein," Free Radical Research, vol. 38, no. 2, pp. 209-216, 2004.

[120] W. L. Hall, G. Rimbach, and C. M. Williams, "Isoflavones and endothelial function," Nutrition Research Reviews, vol. 18, no. 1, pp. 130-144, 2005.

[121] M. Pan, S. Lin-Shiau, C. Ho, J. Lin, and J. Lin, "Suppression of lipopolysaccharide-induced nuclear factor- $\kappa \mathrm{B}$ activity by theaflavin-3,3'-digallate from black tea and other polyphenols through down-regulation of $\mathrm{I} \kappa \mathrm{B}$ kinase activity in macrophages," Biochemical Pharmacology, vol. 59, no. 4, pp. 357-367, 2000.

[122] N. Rajapakse and S. Kim, "Nutritional and digestive health benefits of seaweed," Advances in Food and Nutrition Research, vol. 64, pp. 17-28, 2011.

[123] D. Mozaffarian and J. H. Y. Wu, "(n-3) Fatty acids and cardiovascular health: are effects of EPA and DHA shared or complementary?" Journal of Nutrition, vol. 142, no. 3, pp. 614S625S, 2012.

[124] P. Saravanan, N. C. Davidson, E. B. Schmidt, and P. C. Calder, "Cardiovascular effects of marine omega-3 fatty acids," The Lancet, vol. 376, no. 9740, pp. 540-550, 2010.

[125] M. F.-F. Chong, R. MacDonald, and J. A. Lovegrove, "Fruit polyphenols and CVD risk: a review of human intervention studies," British Journal of Nutrition, vol. 104, supplement 3, pp. S28-S39, 2010.

[126] D. Del Rio, A. Rodriguez-Mateos, J. P. Spencer, M. Tognolini, G. Borges, and A. Crozier, "Dietary (poly)phenolics in human health: structures, bioavailability, and evidence of protective effects against chronic diseases," Antioxidants \& Redox Signaling, vol. 18, no. 14, pp. 1818-1892, 2013.

[127] E. N. Frankel, J. Kanner, J. B. German, E. Parks, and J. E. Kinsella, "Inhibition of oxidation of human low-density lipoprotein by phenolic substances in red wine," The Lancet, vol. 341, no. 8843, pp. 454-457, 1993.

[128] Y. B. De Rijke, P. N. M. Demacker, N. A. Assen, L. M. Sloots, M. B. Katan, and A. F. H. Stalenhoef, "Red wine consumption does not affect oxidizability of low-density lipoproteins in volunteers," American Journal of Clinical Nutrition, vol. 63, no. 3, pp. 329-334, 1996.

[129] M. S. Van Der Gaag, A. Van Tol, L. M. Scheek et al., "Daily moderate alcohol consumption increases serum paraoxonase activity; a diet-controlled, randomised intervention study in middle-aged men," Atherosclerosis, vol. 147, no. 2, pp. 405-410, 1999.

[130] B. Fuhrman, A. Lavy, and M. Aviram, "Consumption of red wine with meals reduces the susceptibility of human plasma and low-density lipoprotein to lipid peroxidation," American Journal of Clinical Nutrition, vol. 61, no. 3, pp. 549-554, 1995.

[131] M. Aviram, M. Rosenblat, D. Gaitini et al., "Pomegranate juice consumption for 3 years by patients with carotid artery stenosis reduces common carotid intima-media thickness, blood pressure and LDL oxidation," Clinical Nutrition, vol. 23, no. 3, pp. 423-433, 2004.

[132] M. D. Sumner, M. Elliott-Eller, G. Weidner et al., "Effects of pomegranate juice consumption on myocardial perfusion in patients with coronary heart disease," American Journal of Cardiology, vol. 96, no. 6, pp. 810-814, 2005.

[133] L. Hooper, G. Madhavan, J. A. Tice, S. J. Leinster, and A. Cassidy, "Effects of isoflavones on breast density in pre-and postmenopausal women: a systematic review and meta-analysis of randomized controlled trials," Human Reproduction Update, vol. 16, no. 6, Article ID dmq011, pp. 745-760, 2010.

[134] T. Jayasena, A. Poljak, G. Smythe, N. Braidy, G. Munch, and P. Sachdev, "The role of polyphenols in the modulation of sirtuins and other pathways involved in Alzheimer's disease," Ageing Research Reviews, 2013.

[135] J. M. Ringman, S. A. Frautschy, E. Teng et al., "Oral curcumin for Alzheimer's disease: tolerability and efficacy in a 24 -week randomized, double blind, placebo-controlled study," Alzheimer's Research \& Therapy, vol. 4, no. 5, p. 43, 2012.

[136] S. Egert and G. Rimbach, "Which sources of flavonoids: complex diets or dietary supplements?" Advances in Nutrition, vol. 2, no. 1, pp. 8-14, 2011. 


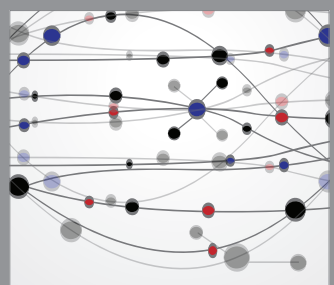

The Scientific World Journal
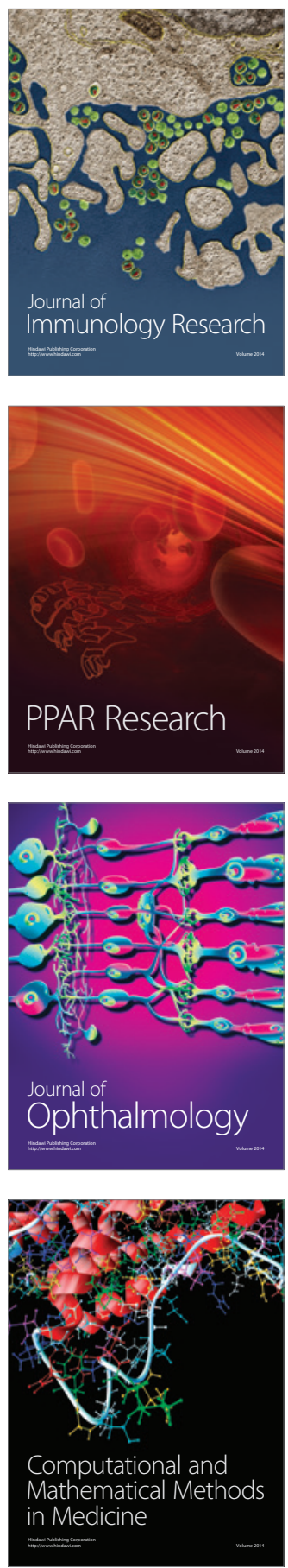

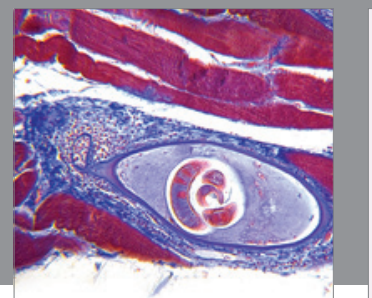

Gastroenterology

Research and Practice
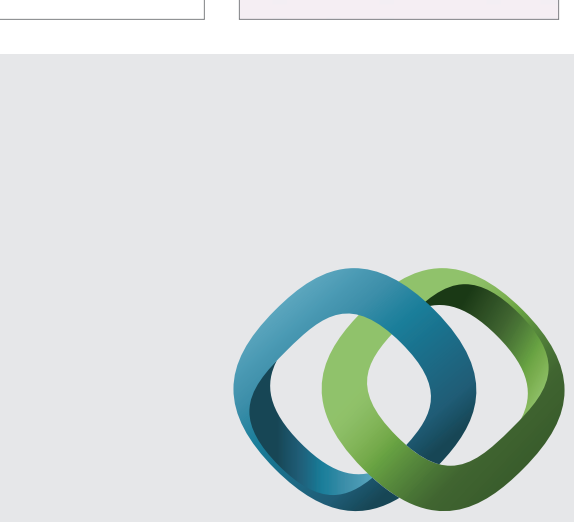

\section{Hindawi}

Submit your manuscripts at

http://www.hindawi.com
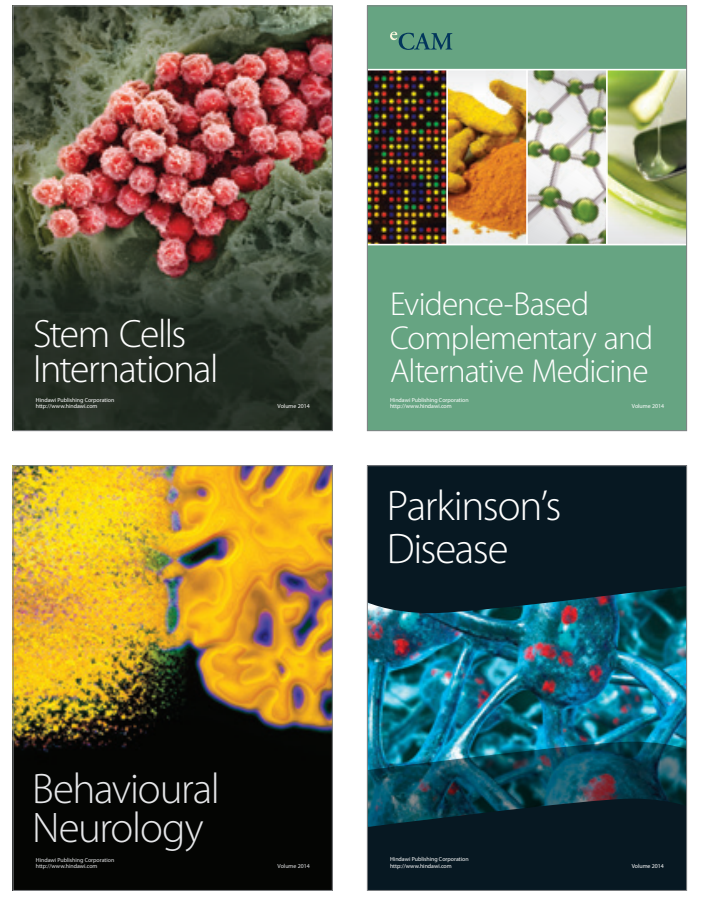
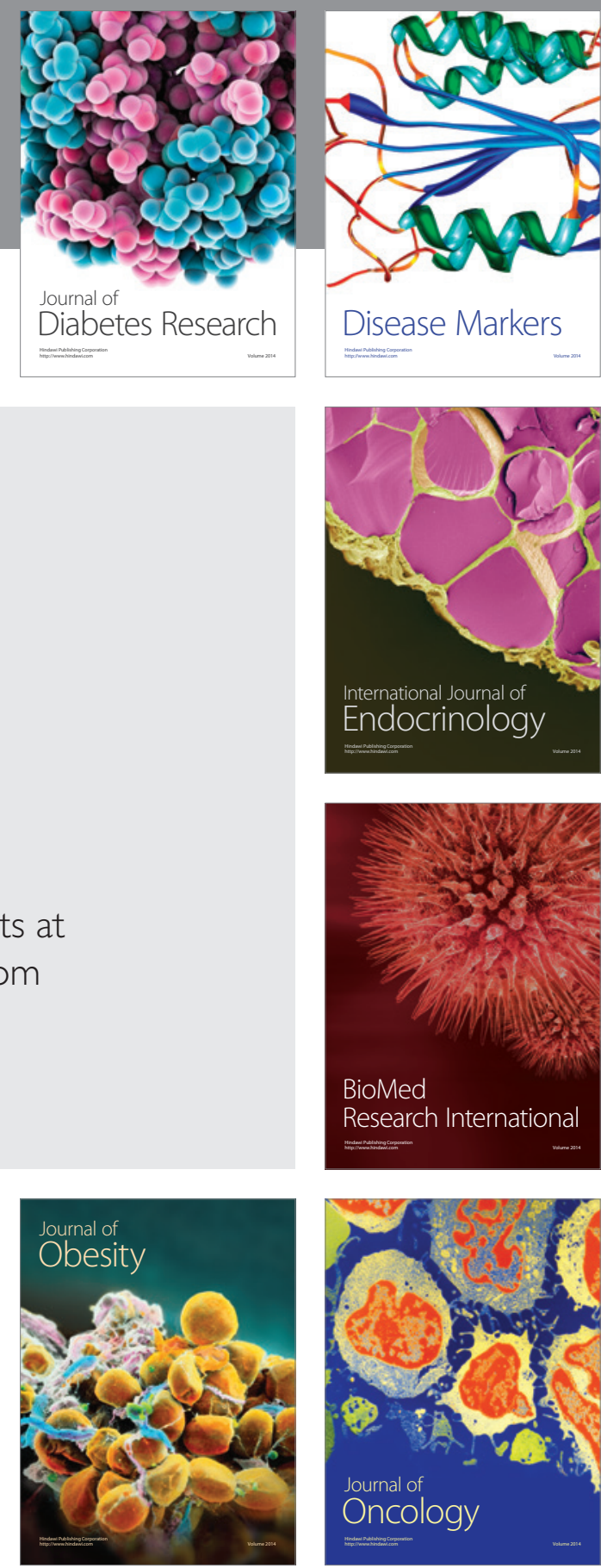

Disease Markers
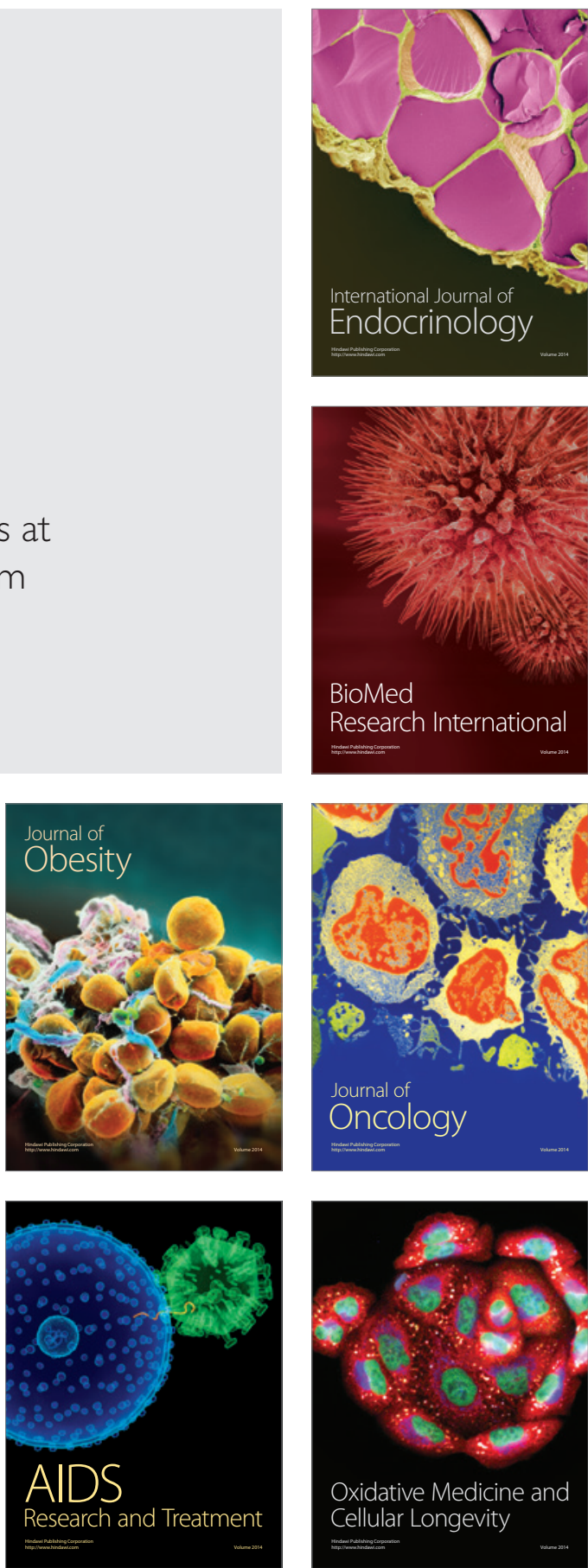